\title{
Weight and Gender Discrimination in the Chinese Labor Market
}

\author{
Suyang Li \\ No.7 High school, Zhengzhou, 450012, China, 2487477636@qq.com
}

\begin{abstract}
At present, most literature nowadays studies weight discrimination in Western countries, but very few of them target China; however, China now has the most obese people in the world. With the focus on weight discrimination in the workplace, this paper will conduct a field experiment focused on whether weight discrimination exists in the context of the Chinese labor market and whether gender discrimination still exists among the overweight and obese population. In the experiment, spurious resumes were sent to real Chinese companies. These resumes are all similar, except for their photos, which can reveal their weight, and biological gender. By comparing the callback rate of all the applicants, we find that weight discrimination does exist in the Chinese labor market, and that women are discriminated against more than men. Then we analyzed the test results according to the national conditions of China.
\end{abstract}

Keywords: obesity, gender, discrimination.

\section{INTRODUCTION}

Weight discrimination in employment has so far been a sensitive and neglected topic in China. The existing literature mostly studies weight discrimination in western countries, and there have never been studies that focused on gender as a variable. According to Nature, the number of obese people worldwide rose from 105 million in 1975 to 641 million in 2014, according to Nature.

\section{OBESITY RISE OVER 40 YEARS}

Data from 1975 to 2014 show that obesity has risen dramatically, more than tripling in men and more than doubling in women.

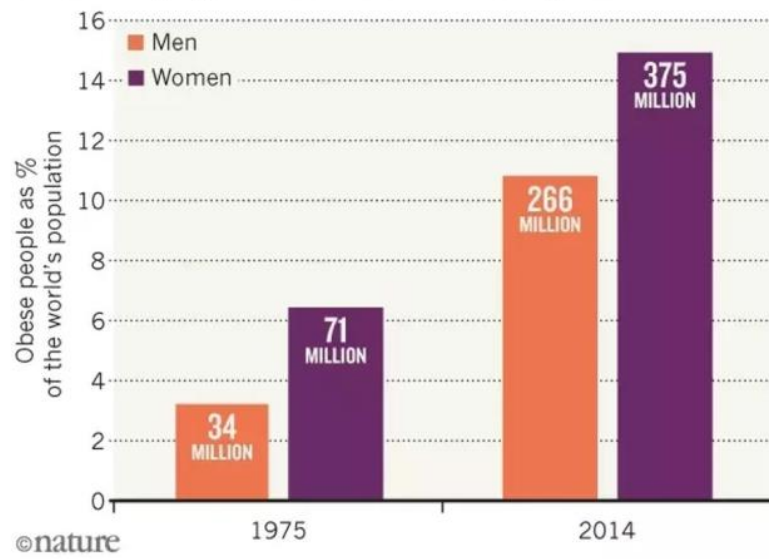

Figure 1. The growth of obesity from 1975 to 2014

As mentioned in 'the Lancet' [1], China has surpassed the United States to become the country with the most obese people in the world. In our experiment, we used photos from the Internet to create two different types of photos - overweight and obese looks - and used these photos to create fake resumes that were then submitted to real companies in China. By classifying these resumes, we got three groups: normal weight (original pictures), overweight, and obese resumes. Firstly, by comparing the callback rates of the three types of photos, we will be able to speculate whether there is weight discrimination in the Chinese labor market. Secondly, by comparing the callback rates of men and women we could infer whether there is gender discrimination in the Chinese labor market under the premise of overweight obesity.

\section{LITERATURE REVIEW}

With the public's interest in the anti-weight discrimination movement, more and more people start to feel confident about their weight. However, we cannot deny that weight discrimination still exists, especially in workplaces. Hiring managers rated obese candidates as less fit to work than normal-weight candidates. Participants' gender and weight status also influenced job applicants' fitness, with higher levels of discrimination against obese applicants in physically demanding occupations [2]. The existing literature mostly talks about the phenomenon of weight discrimination in Western countries, analyzing the reasons for its occurrence, such as the weight discrimination in the American workplace [3]. Inadequate legal protection is the main cause of discrimination. Although most forms of discrimination are prohibited in the United States, Michigan is the only state that prohibits weight 
discrimination in workplaces. Overweight people are not protected from discrimination at work and are unable to seek legal assistance. Even if they have excellent job performance, their employers can still find legitimate business reasons to fire them [4]. Even in literature that discusses Western countries, they only simply expound the existence of discrimination [5]. Our experiment focused on the Chinese context, exploring whether weight discrimination still exists in China, a country with a large population base and a cheap labor force. Secondly, in addition to examining the existence of discrimination, the experiment also used gender as a variable to determine which gender is more discriminated against.

\section{EXPERIMENT DESIGN}

\subsection{Creation of Resumes}

The first step in the experiment was to create a template for the resume. We found a free resume template from Chuizi Resume (https://www.100chui.com) that can be used for job applications. It is important to notice that the application did not involve any real person. Our resumes included the applicant's name, email address, contact number, objective skills, personal experience, education background, and most importantly, the photo. We selected 42 photos of normal weight males (21 photos) and females (21 photos) from Photosearch (http://www.photosearch. com), which we considered appropriate for this study. People in the photos were about 20-30 years old. Each of these normal weight look photos was transformed into overweight and obese look photos by photoshopping through Fatbooth.

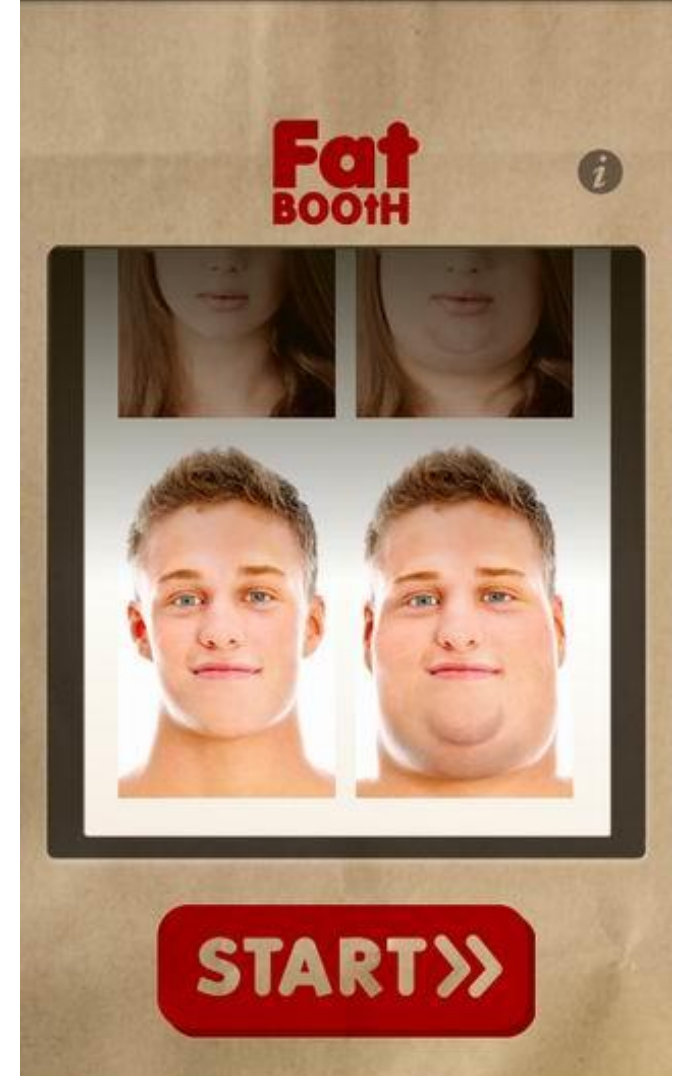

Figure 2. The difference between the usage of Fatbooth

(Overweight and obesity are defined by BMI = weight $(\mathrm{kg}) \div$ height $\left(\mathrm{kg} / \mathrm{m}^{2}\right)$. According to Figure 3 from Health and Care [6], if the BMI is over 25, the person is overweight; if the BMI is over 30 , the person is obese.) Thus, we got 126 resumes: $42 \times 3$. Number ' 42 ' represents the original 42 photos derived from the Internet, and ' 3 ' represents 3 groups-normal weight, overweight and obesity.

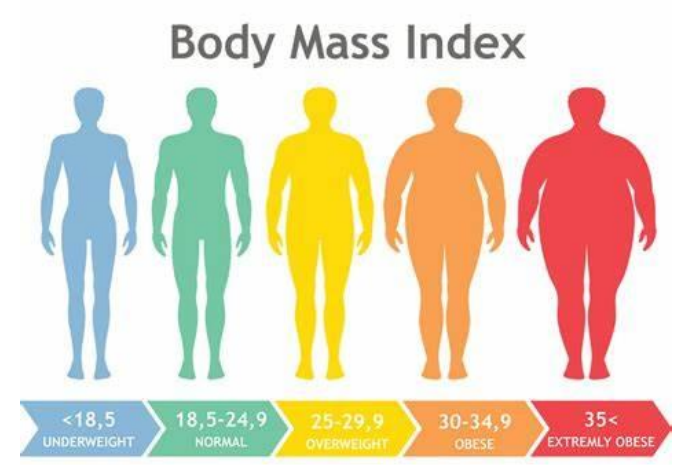

Figure 3. How Do I Calculate My BMI 


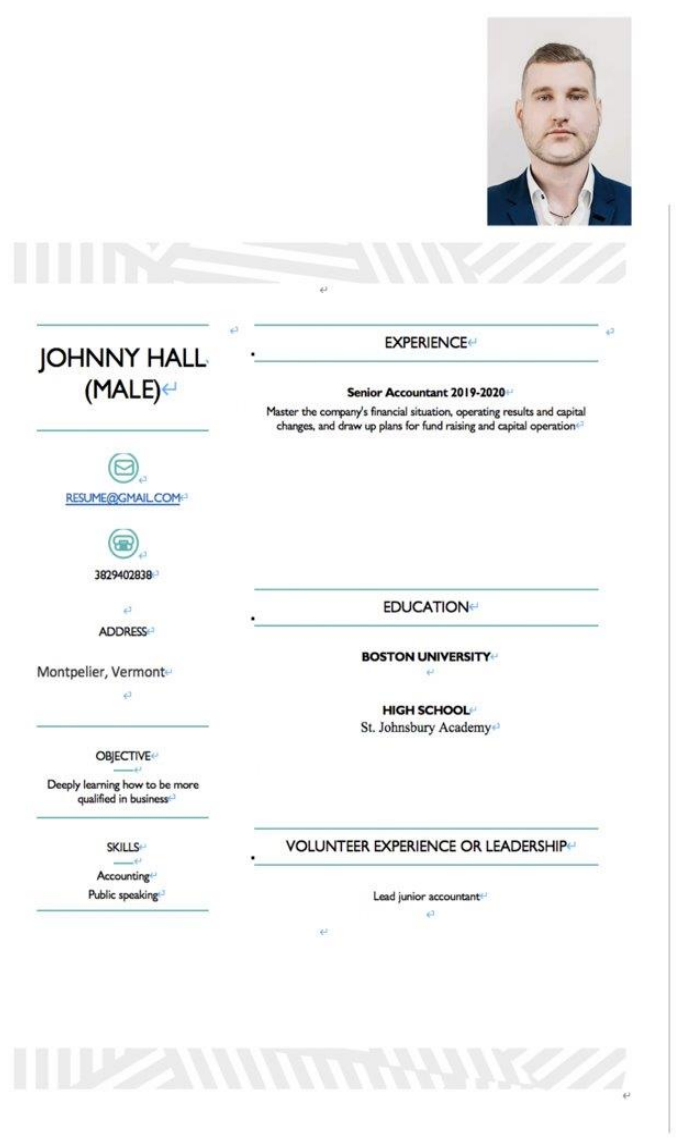

Figure 4. An example of the resume

\subsection{Procedures}

As for the location of the workplace, we focused on big cities, because of the higher opportunities, and the tolerance of diversity. Thus, we targeted Beijing and Shanghai. To avoid gender discrimination, we applied for occupations such as sales manager, accountant and waiter. We wanted to see if targeting obese people could lead to gender discrimination, even in jobs with similar ratios of men to women.

We divided these 126 resumes we sent out into 7 sets of 18 resumes each: three normal weight female applicants, three normal weight male applicants, and the corresponding six overweight and six obese applicants through photoshopping. To avoid suspicion, a company would receive six resumes from different applicants: one from a normal weight woman, one from an overweight woman, one from an obese woman, one from a normal weight woman, an overweight man, and one from an obese man. By using the figure 5 'How a company receives applications' to exemplify, one company will receive normal weight $\mathrm{A}$, overweight $\mathrm{B}$, obese $\mathrm{C}$, normal weight $\mathrm{D}$, overweight $\mathrm{E}$, and obese $\mathrm{F}$.

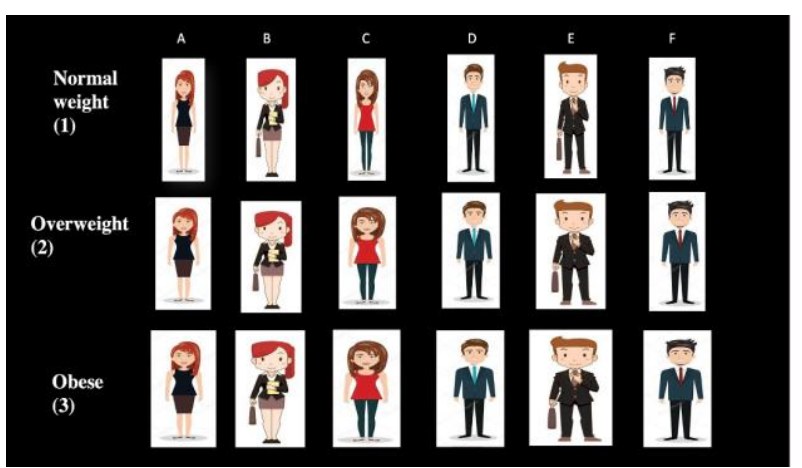

Figure 5. How a company receives applications

\subsection{Measuring Responses}

We measured the callback rate of interview or e-mail of our given resumes. For each phone call or email response, we used the information left by the hiring manager (applicant's name, company name, contact phone number) to match the response with the corresponding resume. In our experiment, because the address is fictitious, hiring managers who contact applicants via the address will not be measured. Suppose a group of 18 resumes has applicants. By using the figure 5 'How a company receives applications', firstly, through horizontal comparison- $\mathrm{A}, \mathrm{B}$, and $\mathrm{C}$ from the same line- of the callback rates of 'the same applicant' we can judge whether weight discrimination exists in Chinese workplace. Secondly, by comparing the total callback rates of male and female, we can judge whether there is gender discrimination against obese applicants in positions with similar gender ratios.

Table 1. MEAN CALLBACK RATES OF THREE KINDS OF WEIGHT APPLICANTS' RESUMES
\begin{tabular}{|l|l|l|l|}
\hline & $\begin{array}{l}\text { Percent of callback } \\
\text { rate for normal } \\
\text { weight applicants }\end{array}$ & $\begin{array}{l}\text { Percent of callback } \\
\text { rate for overweight } \\
\text { applicants }\end{array}$ & $\begin{array}{l}\text { Percent of callback } \\
\text { rate for obese } \\
\text { applicants }\end{array}$ \\
\hline Total Resumes & 7.70 & 6.99 & 6.25 \\
\hline
\end{tabular}




\begin{tabular}{|l|c|c|c|}
\hline Female & 7.56 & 6.71 & 5.92 \\
\hline Male sales & 7.83 & 7.27 & 6.58 \\
\hline $\begin{array}{l}\text { Female as } \\
\text { assistants }\end{array}$ & 7.87 & 6.97 & 6.01 \\
\hline $\begin{array}{l}\text { Males as sales } \\
\text { assistants }\end{array}$ & 8.07 & 7.56 & 6.27 \\
\hline $\begin{array}{l}\text { Females as } \\
\text { accountants }\end{array}$ & 7.56 & 6.63 & 5.88 \\
\hline Males as accountants & 7.98 & 7.23 & 6.71 \\
\hline Females as waiters & 7.24 & 6.53 & 5.95 \\
\hline Males as waiters & 7.43 & 7.01 & 6.76 \\
\hline
\end{tabular}

\subsection{Weakness of the experiment}

Although our experiment has many improvements over the previous studies, there are many shortcomings. Firstly, we only tested whether applicants' callback rate, but whether they will be discriminated against inside companies is not part of our examination. Secondly, our program simply measures call-back interviews, but there may be friction during the actual interview, reducing the number of people who get the job. Third, instead of directly highlighting the applicant's weight, the resume used photos to suggest it. However, some employers might not even notice the names. Fourth, we only applied for jobs on recruitment websites [7]. If real overweight or obese applicants seek jobs through newspapers or offline, our results may be qualitatively affected. Finally, our experiment only looked at three occupations with similar gender ratios. Nevertheless, most occupations do not have similar gender ratios nowadays, and our results would not apply to those occupations.

\section{RESULTS AND DISCUSSIONS}

Table 1 lists the callback rates of applicants of three kinds of weight. First, normal-weight applicants had a 7.7 percent chance of receiving a callback, overweight applicants had a 6.99 percent chance and obese applicants had a 6.25 percent chance of receiving a call back. We can presume that the probability of getting a callback decreases as applicants' weight increases. This may be resulted because of China's huge population, Chinese hiring managers will have more choices. Chinese people place high value on appearance, obese applicants will be at a disadvantage in the workplace. Hiring managers will be more likely to reject overweight or obese applicants.

Second, normal-weight female applicants had a 7.56 chance of getting a callback, and normal-weight male applicants had a 7.83 chance of receiving a call back. Overweight female applicants had a 6.71 percent chance of getting a callback, and overweight male applicants had a 7.27 percent chance of getting a callback. Obese female applicants had a 5.92 percent chance of getting a callback, and obese male applicants had a 6.58 percent chance of receiving a call back. So even in jobs with a similar malefemale ratio, the callback rate for men will be higher and higher than for women as they gain weight. According to Table 1, we can see that in the position of waiter, the callback rate of women is significantly lower than that of men. This phenomenon may be due to the increasing demands on women's appearance in modern society. Even when both male and female applicants are overweight or obese, women are more discriminated against and receive a lower callback rate. Overweight and obese female applicants are discriminated against more as waitress, because waitressing places more emphasis on appearance.

\section{CONCLUSION}

This paper explores, firstly, whether weight affects the recruitment rates in the Chinese workplace. The paper states that the callback rate of overweight applicants is less than normal weight applicants and the callback rate of obese applicants is less than obese applicants. Secondly, in jobs with similar male-female 
ratios, women are significantly discriminated against if they were overweight or if the applicants were obese. These will be of great value to hiring managers. If hiring managers continue to reject obese or overweight applicants, then obese or overweight applicants will apply for positions below their abilities, which often comes with a lower salary. In other words, when the normal-weight applicants, the obese applicants, and the overweight applicants are equally competent, the hiring manager will pay the normal-weight applicants more, followed by the obese applicants, and finally the overweight applicants will get the lowest salary. With a large population and an increasing number of obese people in China, hiring managers need to pay more attention to their weight when making hiring decisions.

\section{REFERENCES}

[1]. Dong, Y. et al. (2019) LANCET DIABETES ENDO, 7(4)

[2]. Stuart, W. et al. (2016) Weight discrimination: a multidisciplinary analysis. Employee Responsibilities and Rights Journal, 12[J], no. 1, pp.9-24.

[3]. Jin, H. (2020) Weight Prejudice in the Workplace in the United States[J]. The Frontiers of Society, Science and Technology, 2(9)

[4]. Sanburn, Y. et al. (2012) The moderating effect of gender as a protective factor against discrimination in migrants from Latin America and China[J]. Journal of Community Psychology, 48(6) : 19641984

[5]. Ming, G. (2019) Chinese Appearance Level Report: Do you also have "appearance anxiety"? https://news.online.sh.cn/news/gb/content/201903/16/content_9230282_2.htm

[6]. Paul. (2017) How Do I Calculate My BMI? https://www.healthandcare.co.uk/blog/how-do-icalculate-my-bmi.html

[7]. Ying, M. (2020) The difference between Chinese and Western food culture [J]. 47 (04):143-144. 